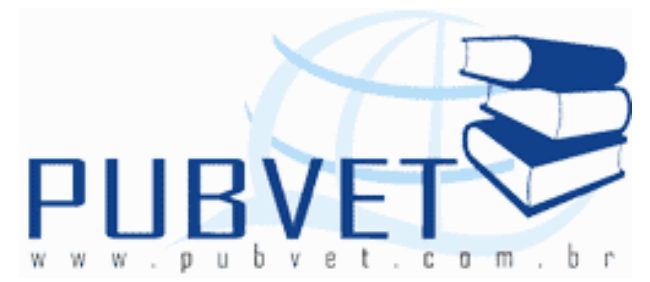

PUBVET, Publicações em Medicina Veterinária e Zootecnia.

\title{
Estudo de caso sobre a bovinocultura de corte: uma análise baseada em custos
}

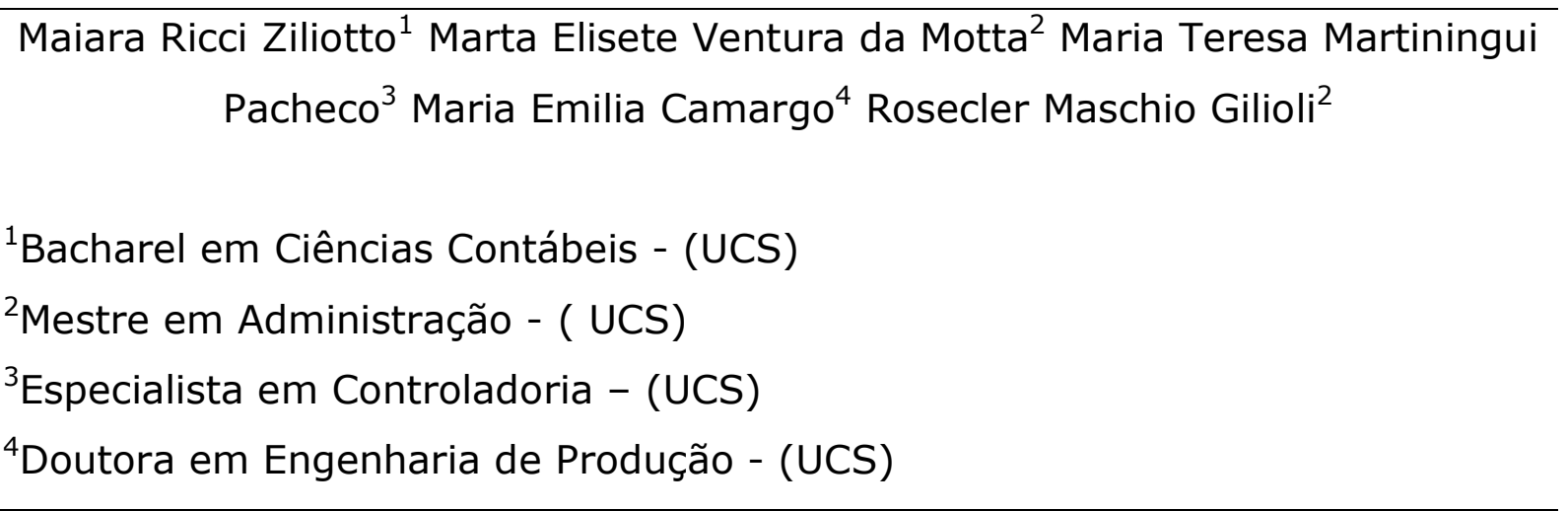

\section{Resumo}

A contabilidade de custos é um instrumento desenvolvido para gerar informações essenciais, utilizadas no controle das operações e nas determinações para as tomada de decisões. O artigo pretende informar e evidenciar através de análises reais, qual dos sistemas de produção do gado de corte, extensivo ou intensivo, atinge objetivos de diminuição dos custos e da maximização dos lucros. Trata-se, portanto, da relevância da análise de custos na engorda da bovinocultura, e quais os benefícios que com a sua aplicação podem ser evidenciados, podendo-se buscar resultados comparativos entre os métodos. Utilizou-se a pesquisa exploratória, operacionalizada através do estudo de caso apresentar uma análise e comparação dos diferentes sistemas de engorda do gado de corte é mais vantajoso ao bovinocultor. Constatou-se que o sistema extensivo possui uma lucrativamente com $27,95 \%$ no sistema 
ZILIOTTO, M.R. et al. Estudo de caso sobre a bovinocultura de corte: uma análise baseada em custos. PUBVET, Londrina, V. 6, N. 2, Ed. 189, Art. 1270, 2012.

intensivo no ano de 2011, sendo que o manejo de pastagens tornou-se mais rentável em relação aos altos custos do confinamento, ratifica-se que o levantamento de custos é de extrema importância para um controle preciso da atividade possibilitando uma melhor análise dos seus resultados.

Palavras-chave: Custo, gado de corte, pastagem, confinamento.

\section{Case study on beef cattle: an analysis based on costs}

\section{Abstract}

Cost accounting is an instrument designed to generate essential information used to control the operations and their measurement for decision making. The article aims to inform and demonstrate through real analysis, which of the production systems of cattle, extensive or intensive, achieves goals of reducing costs and maximizing profits. It is, therefore, the relevance of cost analysis in the fattening of cattle, and what benefits with your application can be demonstrated, and we can get comparative results between the methods. We used the exploratory research, operationalized by presenting a case study analysis and comparison of different systems of fattening of beef cattle is more advantageous to bovinocultor. It was found that the system has an extensive profitably with $27.95 \%$ in the intensive system in 2011, and pasture management has become more profitable at the high costs of confinement, it confirms that the survey cost is extremely important for precise control of the activity allowing a better analysis of their results.

Keywords: Cost, beef cattle, pasture, feedlot.

\section{Introdução}

A pecuária de corte é um dos ramos da agropecuária onde se destina da criação de gado bovino para sua engorda e posterior abate. Esta uma atividade produtora de bens e conseqüentemente geradora de custos, a análise dos 
ZILIOTTO, M.R. et al. Estudo de caso sobre a bovinocultura de corte: uma análise baseada em custos. PUBVET, Londrina, V. 6, N. 2, Ed. 189, Art. 1270, 2012.

mesmos se torna relevante para encarar a bovinocultura de corte de maneira clara e segura, tendo-a como uma empresa.

O custo de produção do gado de corte permite que o produtor concentre um planejamento e controle no seu meio pecuário. A atividade rural como qualquer outra, requer conhecimento financeiro e acompanhamento específico, como a análise dos custos, que é capaz de identificar os componentes que exercem maior influência na produção da carne.

O conhecimento amplo da atividade é de extrema importância, pois através deste o pecuarista avalia seus negócios de forma mais adequada e econômica. Dessa forma, os riscos são menos freqüentes possibilitando ao produtor à tomada de decisões mais conscientemente, de um modo que possa maximizar os lucros e diminuição dos custos.

Além desta seção introdutória, o artigo está organizado nas seguintes seções: fundamentação teórica, metodologia empregada; estudo de caso e considerações finais.

\section{FUNDAMENTAÇÃO TEÓRICA}

\subsection{Contabilidade de Custos}

Conforme Maher (2001, p. 38), "a contabilidade de custos é o ramo da contabilidade que mede, registra e relata informações sobre custos".

Também para Ferreira (2007, p. 25), "a contabilidade de custos é um processo de obtenção de custos e pressupõe a contabilização e registro de informação. Contudo, o que de fato caracteriza a contabilidade de custos são as técnicas empregadas para a sua determinação".

Pode-se afirmar que a contabilidade de custos é o processo, que através da contabilidade geral, registra custos de todas as operações geradas pela empresa. Com os dados obtidos pela contabilidade de custos, os administradores esclarecem os custos de cada produto, podendo assim ter 
ZILIOTTO, M.R. et al. Estudo de caso sobre a bovinocultura de corte: uma análise baseada em custos. PUBVET, Londrina, V. 6, N. 2, Ed. 189, Art. 1270, 2012.

uma visão mais clara do processo produtivo da empresa, buscando assim obter operação mais eficiente, lucrativa e consequentemente econômica.

\subsection{Definições de Custos}

Ao se tratar de Contabilidade de Custos, encontra-se uma dificuldade em resolver o confronto dos significados, pois na maioria das vezes utilizam-se nomes que possuem amplo sentido, como é o caso das palavras custos, despesas, gastos, em fim todas parecem ter o mesmo conceito, pois ao estudar descobre-se que cada palavra possui seu próprio significado.

Gasto, para Martins (2006, p.24), "é a compra de um produto ou serviço qualquer, que gera sacrifício financeiro para a entidade, sacrifício esse representado por entrega ou promessa de ativos".

Custo é o gasto relativo para a produção de bens ou serviços, portanto o custo também é um gasto, é o somatório do esforço físico ou financeiro despendido na produção de um bem ou serviço. (FERREIRA 2007, p. 24)

Dutra (2003, p. 33), define custos como:

A parcela do gasto que é aplicada na produção ou em qualquer outra função de custo, gasto esse desembolsado ou não. Custo é o valor aceito pelo comprador para adquirir um bem ou é a soma de todos os valores agregados ao bem desde a sua aquisição, até que ele atinja o estagio de comercialização.

Despesas são bens ou serviços consumidos direta ou indiretamente, que reduzem o patrimônio líquido. Sendo assim, pode-se dizer que a despesa é o dispêndio ocorrido fora da área de produção de um bem ou serviço. É o esforço financeiro relativo á realização de uma venda. (FERREIRA 2007, p. 24)

Kroetz (2001, p.12) afirma que:

Para diferenciar custos de despesas é importante compreender que primeiramente a entidade realiza o gasto (aumento de obrigações e/ou diminuição do ativo), este gasto pode ser um investimento (aquisição de bens 
ZILIOTTO, M.R. et al. Estudo de caso sobre a bovinocultura de corte: uma análise baseada em custos. PUBVET, Londrina, V. 6, N. 2, Ed. 189, Art. 1270, 2012.

imobilizados, compra de matéria-prima etc.) ou ser um consumo direto (Ex.: pagamento de energia elétrica). Quanto ao investimento este se transformará em despesa em decorrência de sua utilização (depreciação, custo do produto fabricado etc.), após passa a ser classificado como um custo e quando levado para a apuração do resultado (segundo os PFC - a despesa existe em função da receita), transforma-se numa despesa. Já o gasto consumido imediatamente, classifica-se inicialmente como despesa, sendo que estas despesas podem ser relacionadas diretamente com o resultado do exercício, se não participarem do ciclo produtivo. Porém, se identificadas com atividade de produção serão consideradas custo e posteriormente despesas, na fase de apuração do resultado.

Conclui-se que a despesa são gastos relativos às áreas administrativas e comercial de uma empresa, representam sacrifícios no processo de obtenção de receitas, são itens que reduzem o Patrimônio.

Desembolso é o pagamento de parte ou do total adquirido, elaborado ou comercializado. Ele ocorre após a aquisição da propriedade de um bem ou serviço, porém antes ou após sua posse. (DUTRA 2003, p. 33)

Investimento, conforme Martins (2006, p. 25) são:

Os sacrifícios havidos pela aquisição de bens ou serviços (gastos) que são "estocados" nos Ativos da empresa para baixa ou amortização quando sua venda, de seu consumo, de seu desaparecimento ou de sua desvalorização são especificamente chamados de investimentos.

Conforme Martins, a matéria-prima é um gasto contabilizado temporariamente como investimento circulante, já a máquina se transforma num investimento permanente e ações adquiridas de outras empresas são 
ZILIOTTO, M.R. et al. Estudo de caso sobre a bovinocultura de corte: uma análise baseada em custos. PUBVET, Londrina, V. 6, N. 2, Ed. 189, Art. 1270, 2012.

gastos classificados como investimentos circulantes ou permanentes. (MARTINS 2006, p. 25)

Então se diferenciam investimentos como gastos efetuados que se transformam em um investimento, pois são custos imobilizados.

Perda é um gasto involuntário e anormal que ocorre sem intenção de obtenção de receita. Portanto o material excedente no processo produtivo também é um custo, mesmo não integrando o produto final, pois se trata de esforço empreendido para obtenção de receitas. Já os materiais perdidos por acidentes se constituem perdas. (DUTRA 2003, p. 33)

Perda são itens que vão diretamente à conta de Resultado, assim como as despesas, mas não representam sacrifícios normais ou derivados de forma voluntária das atividades destinadas à obtenção da receita. É muito comum o uso da expressão Perdas de material na produção de inúmeros bens e serviços; entretanto, a quase totalidade dessas perdas é, na realidade, um custo, já que são valores sacrificados de maneira normal no processo de produção, fazendo parte de um sacrifício já conhecido até por antecipação para a obtenção do produto ou serviço e da receita almejada. (MARTINS 2006, p. 26)

Em outras palavras, podem ser definidas como situações anormais das operações rotineiras da empresa. Não é um sacrifício feito com intenção de obtenção de receita.

\subsection{Custos diretos}

Conforme, Ferreira (2007, p. 53), "os custos diretos entendem-se aqueles que podem ser imediatamente apropriados a um só tipo de produto ou a um só tipo de serviço. Especificamente, são aqueles que podem ser apropriados diretamente a uma função de acumulação de custos". 
O que define a classificação desse custo como direto é a possibilidade de conhecer a parcela aplicada em cada um dos diferentes produtos que 0 recebem, no momento da sua aplicação. (FERREIRA 2007, p. 53)

\subsection{Custos indiretos}

Martins (2006, p.49) ensina: "cada vez que é necessário utilizar qualquer fator de rateio para a apropriação ou cada vez que há o uso de estimativas e não de medição direta, fica o custo incluído como indireto".

Os Custos Indiretos são também chamados de Gastos Gerais de Fabricação, podendo ser fixos ou variáveis, sendo estes custos divididos em Mão-de-obra Indireta, Materiais Indiretos e Outros Custos Indiretos Fabricação. Maher (2001, p.68), define esses grupos apresentados no Quadro 1:

\begin{tabular}{|l|l|r|}
\hline \multirow{2}{*}{$\begin{array}{l}\text { Mão-de-obra } \\
\text { Indireta }\end{array}$} & $\begin{array}{l}\text { custo dos operários que não trabalham } \\
\text { diretamente com o produto, mas que são } \\
\text { necessários à operação da fabrica. São os } \\
\text { supervisores, operários que trabalham em } \\
\text { manutenção e operários que trabalham com controle } \\
\text { do almoxarifado, por exemplo }\end{array}$ \\
\hline Materiais & $\begin{array}{l}\text { Lubrificantes das máquinas, materiais de polimento e } \\
\text { Indiretos }\end{array}$ & $\begin{array}{l}\text { lampeza, componentes para conserto de máquinas, } \\
\text { lampadas etc., que não integram o produto acabado } \\
\text { mas são necessários a sua fabricação }\end{array}$ \\
\hline $\begin{array}{l}\text { Outros Custos } \\
\text { Indiretos de de } \\
\text { Fabricação }\end{array}$ & $\begin{array}{l}\text { Depreciação do edifício da fábrica e dos } \\
\text { equipamentos, impostos sobre os ativos da fabrica, } \\
\text { seguro do edifício da fábrica e dos equipamentos aí } \\
\text { instalados, aquecimento, força, e gastos } \\
\text { semelhantes, necessários à operação da fábrica }\end{array}$ \\
\hline
\end{tabular}

Quadro 1: Custos Indiretos

Fonte: Maher, (2001, p.68) 
ZILIOTTO, M.R. et al. Estudo de caso sobre a bovinocultura de corte: uma análise baseada em custos. PUBVET, Londrina, V. 6, N. 2, Ed. 189, Art. 1270, 2012.

\subsection{Custos fixos}

Para Hansen e Mowen (2003, p. 88), "os custos fixos são constantes dentro de uma faixa relevante enquanto o nível do direcionador de atividade varia".

Portanto, os custos fixos se mantêm inalterados, qualquer que seja o volume produzido. Mas ao analisar os custos fixos unitários nota-se que há alterações conforme as flutuações na atividade produtiva da empresa. Tem-se como exemplo típico, o aluguel do prédio da fábrica, salário de operadores de máquinas entre outros.

\subsection{Custos variáveis}

Maher (2001, p. 75), define os Custos Variáveis como sendo os "custos que se alteram na produção direta da alteração no volume, dentro de um intervalo relevante de atividade".

Para Hansen e Mowen (2003, p. 89), custos variáveis são definidos como "custos que no total variam em proporção direta às mudanças em um direcionador de atividade".

\subsection{Pecuária de Corte}

A definição para gado conforme Marion (2010, p. 3), "são animais geralmente criados no campo, para serviços de lavoura, para consumo doméstico ou para fins industriais e comerciais. Como os bovinos, suínos, caprinos, equinos, ovinos, muares etc".

A pecuária se destina à domesticação de animais tanto para usos comuns como para ganhos econômicos. Os bovinos também são chamados de Gado Vacum, servem para muitas finalidades, para o trabalho, reprodução, corte e também para leite.

Existem dois tipos de pecuária, segundo Chielle et al. (2008, p. 1), conforme Quadro 2. 


\begin{tabular}{|c|c|}
\hline & $\begin{array}{l}\text { Destinada à criação de rebanhos com objetivo de } \\
\text { produção de carne para o consumo humano. Na } \\
\text { intensiva, o gado é criado confinado ou em } \\
\text { pequenos espaços, alimentado com ração específica. } \\
\text { Neste tipo de criação, a carne produzida é macia e } \\
\text { de boa qualidade para o consumo. Pode ser também } \\
\text { pecuária extensiva (o gado é criado solto e } \\
\text { alimenta-se de pastagem). A carne produzida é } \\
\text { dura, pois o gado desenvolve uma musculatura } \\
\text { rígida e forte devido a necessidade de locomoção } \\
\text { para alimentar - se. }\end{array}$ \\
\hline Pecuária & $\begin{array}{l}\text { te e seus derivad } \\
\text { etc). }\end{array}$ \\
\hline
\end{tabular}

\section{Quadro 2: Tipos de Pecuária}

Fonte: Chielle et al. (2008, p.1)

Os pecuaristas têm como objetivo a produção do gado de corte que seja mais lucrativa dentro de suas condições ambientais. Sendo assim, utilizam os recursos disponíveis, levando em conta as condições de temperatura, umidade, doenças e parasitoses encontradas na área. Quando o produtor pensa a longo prazo, um animal leve e a qualidade da carcaça pode, facilmente se levada a extremos. (WILLIAMS, 1967, p. 106)

É uma atividade com geração de rendimentos, mas deve ser cuidadosamente praticada pelos pecuaristas, o conhecimento do manejo do gado e visão de mercado são essenciais para os criadores obterem um rebanho de porte para obtenção de lucro e confiança de mercado. 
ZILIOTTO, M.R. et al. Estudo de caso sobre a bovinocultura de corte: uma análise baseada em custos. PUBVET, Londrina, V. 6, N. 2, Ed. 189, Art. 1270, 2012.

\subsection{Pecuária na cidade de Vacaria}

Conforme Prefeitura Municipal de Vacaria (2011) foram os missionários jesuítas por volta de 1700 iniciaram a colonização da região deixando o gado para criarem-se soltos trazidos das Missões, sendo denominada "Baqueria de los Pinhales" (Vacaria dos Pinhais). A estrada das tropas, aberta em 1727 e 1729, destinada primeiramente ao comércio de gado, ligou a região dos Campos de Cima da Serra a Lages, Curitiba e São Paulo. Em 1697, os Padres Espanhóis, saindo das Missões, adentravam os nossos campos com a primeira leva de gado vacum. Em 1713 os índios das Missões abriram picadas nos futuros Matos Castelhanos e Português, penetrando o Planalto, ou seja, a região jesuítica da Vacaria dos Pinhais. Às passagens foram abertas abrindo caminho para passar os primeiros gados.

Com o aumento dos rebanhos, os jesuítas passaram a procurar novas pastagens para criação do gado. Encontraram os campos almejados em Vacarias, que se estendia de Santa Maria até o Rio do Prata. No nordeste do Estado foi constituída a Vacaria dos Pinhais. Esta além da qualidade dos campos, oferecida relativa segurança aos rebanhos, em decorrência de suas divisas naturais. Por decisão dos jesuítas, em 1712, os índios tropearam para a Vacaria dos Pinhais 80.000 vacas, as quais ficaram abandonadas, até atingirem um milhão de cabeças. (MARCANTÔNIO 1987, p. 23)

A história da ocupação dos campos de cima da serra, onde se formou mais tarde a cidade de Vacaria, iniciou no fim do século XVII, com a criação de bovinos e foi por seu intermédio que a cidade cresceu.

No entanto, com a estabilização do gado na região nordeste do estado do Rio Grande do Sul, o rebanho começou a reproduzir-se sem a intervenção do homem. Tornando-se a atividade predominante no município, e ainda permanece a influência na cidade, como se pode observar no Quadro 3 a ocupação bovina no município em 26 de abril de 2011. 
ZILIOTTO, M.R. et al. Estudo de caso sobre a bovinocultura de corte: uma análise baseada em custos. PUBVET, Londrina, V. 6, N. 2, Ed. 189, Art. 1270, 2012.

\begin{tabular}{|l|l|l|}
\hline Município & Propriedades/Produtores & No $^{\circ}$ cabeças \\
\hline Vacaria & 1.268 & 66.944 \\
\hline
\end{tabular}

Quadro 3: Ocupação bovina em Vacaria

Fonte: DALPIAS, Luis Cesar (2011)

Conforme dados do IBGE, o município de Vacaria, apresenta valor adicionado bruto da agropecuária a preços correntes, apresentado na Figura 1.

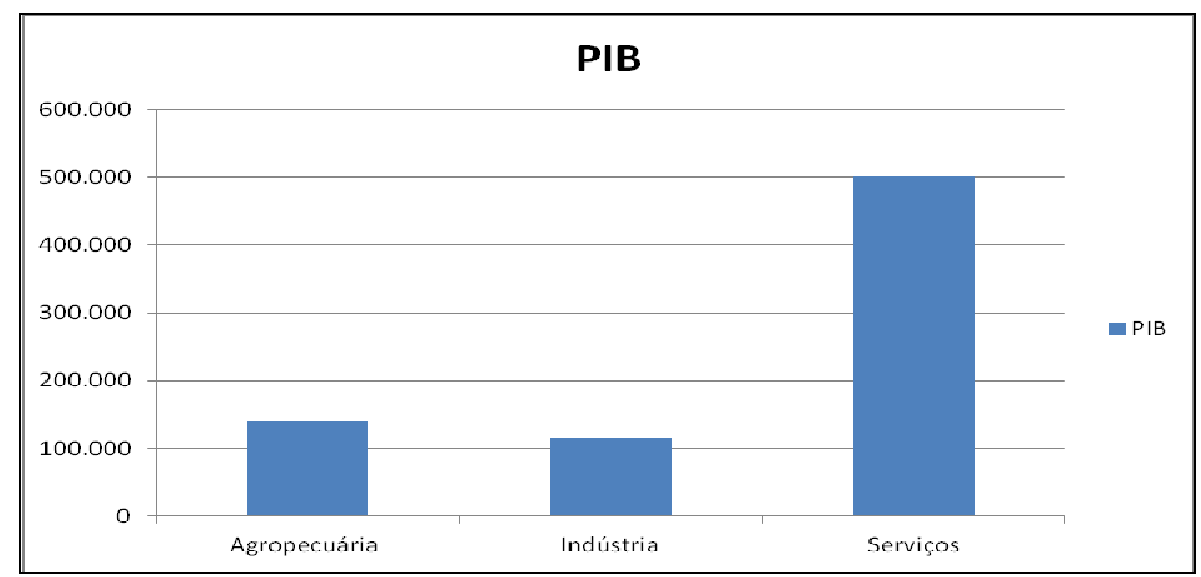

Figura 1: Produto Interno Bruto de Vacaria em 2009.

Fonte: IBGE, www.ibge.gov.br/cidadesat. IBGE, em parceria com os Órgãos Estaduais de Estatística, Secretarias Estaduais de Governo e Superintendência da Zona Franca de Manaus - SUFRAMA.

Atualmente a agropecuária representa grande parte do PIB do município de Vacaria, visto que os números indicados demonstram que as técnicas adotadas no inicio das atividades econômicas da cidade continuam sendo utilizados. Isto é uma demonstração de que o setor representa uma parcela de grande relevância na economia do município, no ano em que o produto foi produzido e comercializado, o valor adiconado representa 140.143, na indústria 115.327 e em serviços representando o maior número em 500.748. 
ZILIOTTO, M.R. et al. Estudo de caso sobre a bovinocultura de corte: uma análise baseada em custos. PUBVET, Londrina, V. 6, N. 2, Ed. 189, Art. 1270, 2012.

\subsection{Método de produção da pecuária}

Para dar início a atividade da pecuária, é necessário ter conhecimento das práticas adotadas para a criação de bovinos de corte, como os princípios gerais da alimentação, o manejo, as instalações, as condições sanitárias, a compra e a venda, em fim tudo que é necessário para a domesticação do gado com fins econômicos. Sendo que existem fases específicas para cada estágio do rebanho, desde seu nascimento até o seu abate.

Conforme Cezar et al. (2005, p.8):

A bovinocultura de corte é desenvolvida em todos os Estados e ecossistemas do Brasil, com grande variabilidade, expressa na densidade dos bovinos nas diferentes regiões, nas taxas de crescimento dos rebanhos e nos sistemas de produção praticados. Estes desenvolvem as fases de cria, recria e engorda, de forma isolada ou em combinação, e utilizam pastagens nativas e cultivadas, associadas ou não à suplementação alimentar em pastagem e em confinamento.

A pecuária de corte apresenta três segmentos distintos: a cria, a recria e a engorda. Para Neumann et al. $(2006$, p. 7$)$ na cria, "o rebanho está voltado à reprodução animal, onde o bezerro é normalmente afastado da mãe entre os oito e dez meses de idade. Na recria, o bezerro, permanece de um ano a um ano e meio e é então destinado para a engorda".

Como visto, existem três fases distintas, na atividade de pecuária de corte, pelas quais passam o animal que se destina para o abate: a cria, a recria e a engorda.

Conforme demonstrado por Corrêa et al. (2009, p. 4), segundo dados do IBGE (2000) apud Lazzarini Neto (2000), "na pecuária de corte brasileira, nos setores de cria e recria de bovinos, acham-se envolvidos $78 \%$ dos pecuaristas do país, que detêm $55 \%$ do total do rebanho nacional".

$\mathrm{Na}$ Figura 2 salientam-se os números de produtores que efetuam a cria e a recria conjuntamente. No entanto, estão fora os produtores que efetuam a cria e a engorda conjuntamente, a recria/engorda e a cria/recria/engorda. 


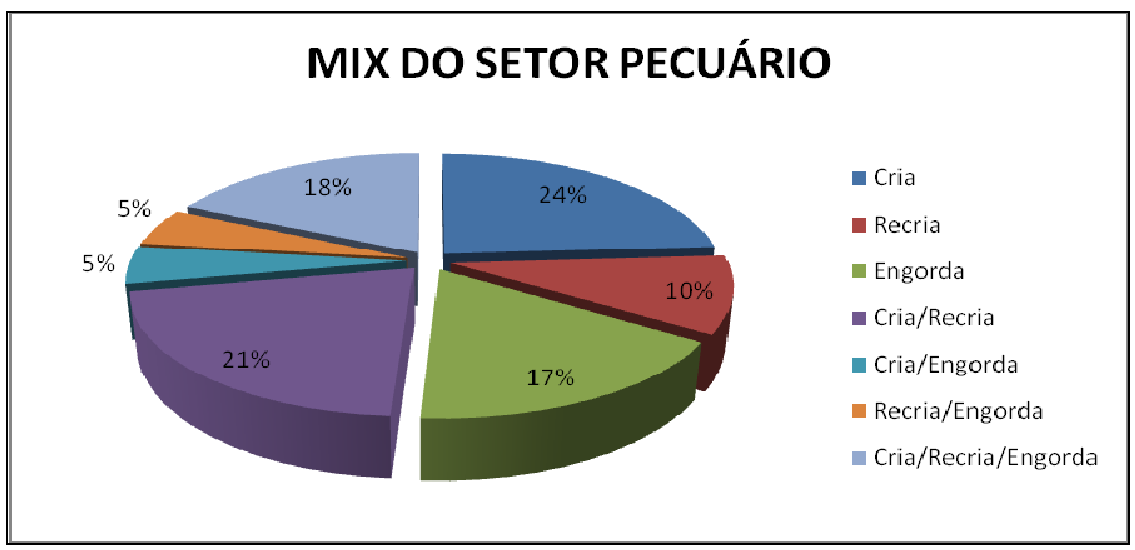

\section{Figura 2: "Mix" do Setor Pecuário - Estrutura da produção de acordo com o tipo de exploração.}

Fonte: IBGE/SDF Consultoria Rural apud Lazzarini Neto.

Segundo Corrêa et al. (2009, p. 4), "a cria é desenvolvida caracteristicamente por pequenos e médios pecuaristas. Normalmente explorase a cria em terras de baixa fertilidade, estando bastante difundido o conceito de que a vaca pare bezerro em qualquer qualidade de terra".

Ainda segundo Corrêa et al. (2009, p. 8), "pode-se afirmar que na cria, devido à complexidade dos fatores que afetam o processo, o produtor deverá então avaliar e planejar a atividade enfrentando duas grandes frentes de trabalho, uma que abrigue o rebanho e outra a propriedade".

No sistema de cria cuidados básicos deverão ser tomados para obter a máxima qualidade de terneiros, o melhoramento genético é uma das responsabilidades dos criadores, pois os compradores procuram animais de excelência, com uma carcaça de alto nível, tendo as obrigações de sanidade em dia, em fim as qualidades que satisfaçam as expectativas dos consumidores, pois assim o produto final (bezerros) com superioridade traz uma confiança de mercado para os criadores perante seus compradores, trazendo assim uma estabilidade para seus negócios.

Quanto a recria, são os bezerros destinados à comercialização, a atividade básica é a produção e a venda do novilho magro para fins de engorda. 
ZILIOTTO, M.R. et al. Estudo de caso sobre a bovinocultura de corte: uma análise baseada em custos. PUBVET, Londrina, V. 6, N. 2, Ed. 189, Art. 1270, 2012.

A fase da recria, onde o gado permanece por maior tempo, desde a sua desmama até a engorda, se caracteriza pela grande formação de massa muscular e o desenvolvimento da estrutura óssea do animal. No fim desta etapa, o bovino estará com carcaça suficiente para se obter sucesso na fase seguinte. (CORRÊA et al. 2009, p. 8)

$\mathrm{Na}$ fase de acabamento, a engorda, é a mais importante, pois é através dela que se demonstra a resumo de todos os processos produtivos da pecuária de corte, assim tudo que foi desenvolvido durante as demais etapas serão tiradas como conclusão nesta, pois, é o gado pronto para o abate, que se torna atrativo para o consumidor final. (CORRÊA et al. 2009, p.13)

Conforme Cezar et al. (2005, p. 18):

$\mathrm{Na}$ engorda ou terminação, nas décadas passadas foi exercida pelos chamados "invernistas". Estes se localizavam em regiões de boas pastagens e aproveitavam a grande oferta de boi magro (24 a 36 meses de idade) da época. Atualmente, encontra-se bastante restrita como atividade isolada, sendo desenvolvida por um número reduzido de pecuaristas que também fazem a terminação de fêmeas. Essa mudança de cenário deve-se à expansão das áreas de pastagens cultivadas em regiões onde tradicionalmente não existiam e, por conseqüência, à redução da oferta de boi magro.

Como consequência do acréscimo do cultivo de pastagens, a oferta de boi magro torna-se escassa, pois até alguns anos atrás, o processo de produção era diferente, haviam os criadores e os invernadores, ficando estes com o processo final de engorda e venda para o frigorífico. Hoje, o cenário é diferente, o pecuarista realiza as três fases de produção, resultando na redução de boi magro para a venda.

Pode-se dizer que é na fase de engorda que a produção de carne é uma tarefa onde se deve levar em conta, com grande proporção, a exigência da 
ZILIOTTO, M.R. et al. Estudo de caso sobre a bovinocultura de corte: uma análise baseada em custos. PUBVET, Londrina, V. 6, N. 2, Ed. 189, Art. 1270, 2012.

excelência do produto. Assim, para que todo o processo, desde o nascimento até seu abate, seja de qualidade, há a necessidade de um comprometimento dos criadores quanto à escala, somente assim pode-se atender aos consumidores de forma adequada e segura.

Assim a pecuária de corte é uma atividade dividida na criação de gado para o comércio e na criação de gado de elite (reprodutores e matrizes, de extrema qualidade). Portanto a cria compreende o período de cobertura até o desmame, a recria do período entre a desmama até a fase de terminação, e a engorda pode ser feita a pasto ou a confinamento.

\subsection{Sistema de Produção}

Sistema de produção do gado de corte para Euclides Filho (2000, p. 9), entende-se assim:

[...] o conjunto de tecnologias e práticas de manejo, bem como o tipo de animal, o propósito da criação, a raça ou grupamento genético e a ecorregião onde a atividade é desenvolvida. Devem-se considerar, ainda, ao se definir um sistema de produção, os aspectos sociais, econômicos e culturais, uma vez que esses têm influência decisiva, principalmente, nas modificações que poderão ser impostas por forças externas e, especialmente, na forma como tais mudanças deverão ocorrer para que o processo seja eficaz, e as transformações alcancem os benefícios esperados. Permeando todas essas considerações, devem estar a definição do mercado e a demanda a ser atendida, ou seja, quais são e como devem ser atendidos os clientes ou consumidores.

Sob o ponto de vista gerencial, não existe um sistema único de manejo de rebanhos. A adequação não está diretamente ligada ao desejo do produtor, também depende das condições de cada região, cultura do pecuarista, da 
ZILIOTTO, M.R. et al. Estudo de caso sobre a bovinocultura de corte: uma análise baseada em custos. PUBVET, Londrina, V. 6, N. 2, Ed. 189, Art. 1270, 2012.

qualidade do gado, enfim, o produtor define o método mais adequado para alcançar seus objetivos ou atender a demanda do mercado.

A pecuária de corte brasileira é desenvolvida em todos os Estados do País, tanto pode ser extensiva, onde suportam pastagens nativas e cultivadas com pouca utilização de insumos para sua fertilidade, como também intensiva composta por pastagens de alta produtividade, suplementação alimentar em pasto e confinamento. Portanto, a atividade caracteriza-se pela predominância de uso de pastagens. (CEZAR et al. 2005, p. 10)

No Rio Grande do Sul, a pecuária de corte se destaca pela tradição da produção com base em pasto natural, contando com cerca de $90 \%$ deste, e campos melhorados ou de pastagens cultivadas. Sendo que, no confinamento a alimentação é formada por grãos excedentes da produção agrícola e por volumosos, como silagens e feno. (NEUMANN et al. 2006, p. 2)

\subsection{Sistema Extensivo}

Conforme Grande Manual Globo (vol.4, p.174):

O Sistema Extensivo se caracteriza por manter a criação exclusivamente a campo, aproveitando ao máximo os recursos naturais, com economia de instalações, equipamentos e mão-de-obra. Nesse sistema o gado encontra a alimentação principal na pastagem natural. É um sistema de criação muito comum e adotado particularmente na criação de gado comum ou misto, em grande escala, visando-se a criação de novilhos para o abate. Os melhoramentos introduzidos, sem modificar o caráter do regime, são simplesmente para favorecer a criação de um gado de mais valor e mais exigente.

Conclui-se então que para o sistema extensivo ser de qualidade, dependerá do conhecimento apropriado do criador para o manejo do gado, pois para o sistema atingir a excelência, tem de ter cuidados básicos como, a idade do rebanho, a qualidade dos pastos e a rapidez que se deseja do 
ZILIOTTO, M.R. et al. Estudo de caso sobre a bovinocultura de corte: uma análise baseada em custos. PUBVET, Londrina, V. 6, N. 2, Ed. 189, Art. 1270, 2012.

aumento de peso. Deve-se levar em conta a superlotação das pastagens, e também as condições de mercado, são princípios básicos para atingir resultados significativos neste método.

\subsection{Sistema Semi-intensivo}

O sistema semi-intensivo é um método utilizado pelos pecuaristas que almejam engordar uma quantidade maior de gado em um espaço mais reduzido, principalmente em zonas suburbanas, ou mesmo em regiões coloniais, porém estas são utilizadas em maior proporção para agricultura. Neste sistema os animais são soltos em pastos e também recebem em estábulos por algumas horas diárias, ração como suplementação. (GRANDE MANUAL GLOBO vol.4, p.174)

\subsection{Sistema Intensivo}

No sistema intensivo, como é o caso do confinamento, o gado é alimentado em cochos, com rações. O rebanho fica em um espaço restrito, onde a movimentação se torna difícil. Muitos criadores utilizam deste método, pois o gado tem um ganho de peso mais rápido devido a estas condições.

Ainda de acordo com o Grande manual Globo (vol. 4, p.174), o Sistema Intensivo em relação aos outros, "se caracteriza principalmente pelo emprego de maior capital e mais trabalho em relação à área. A alimentação básica constitui-se de forrageiras e complementos à base de rações e concentrados".

\subsection{Pastagens}

Pastagem é o principal insumo da pecuária de corte e leite. Segundo Kichel e Kichel, (2001 p.01) estas "devem apresentar boa produtividade, qualidade, palatabilidade e longevidade. Para que isso ocorra, alguns procedimentos ou técnicas de baixo custo devem ser adotados, ou até mesmo o não aumento de custos".

Lazzarini Neto (2000, p.61) afirma que de todo modo, é preciso aumentar a produtividade das pastagens, pois quanto mais produtivas 
ZILIOTTO, M.R. et al. Estudo de caso sobre a bovinocultura de corte: uma análise baseada em custos. PUBVET, Londrina, V. 6, N. 2, Ed. 189, Art. 1270, 2012.

suportam maior quantidade de cabeças, proporcionando maior ganho de peso. Assim pode-se alargar a lotação sem os animais sentirem falta de pasto. $O$ resultado desse fato não poderia ser outro a não ser maior lucro para o pecuarista.

Acredita-se que desta forma, a criação de gado de corte requer do pecuarista elaboração de estratégias para lidar com as pastagens, pois a falha do manejo com as mesmas resultam a baixos níveis de nutrição dos animais, reduzindo a produtividade do rebanho bovino, diminuindo assim a sua lucratividade.

\subsection{Classificação}

De acordo com Cezar et al. (2005, p. 15), as pastagens "são os componentes mais importantes da produção de carne bovina em todas as regiões do País. Basicamente, essas áreas se constituem de pastagens perenes, ocorrendo em menor escala pastagens cultivadas de ciclos anuais".

Segundo Marion (2010, p.49):

A pastagem natural é também denominada pasto nativo e constituída de áreas não cultivadas, utilizadas para pastagens, das quais se aproveita o potencial natural (campos, cerrados, capins naturais, etc). Geralmente, são áreas de boa cobertura vegetal que não apresentam grandes problemas de erosão. Esse tipo de pasto sofre melhoramentos esporádicos.

As pastagens naturais são formadas sem a intervenção do homem, são constituídas de plantas nativas. De acordo com Jardim (1973, p. 171), estas compreendem três grupos, explicitados no Quadro 4. 
ZILIOTTO, M.R. et al. Estudo de caso sobre a bovinocultura de corte: uma análise baseada em custos. PUBVET, Londrina, V. 6, N. 2, Ed. 189, Art. 1270, 2012.

\begin{tabular}{|l|l|}
\hline Campos & $\begin{array}{l}\text { Predomina a vegetação herbácea, principalmente } \\
\text { gramínea, mas às vezes com boa ocorrência de } \\
\text { leguminosas. }\end{array}$ \\
\hline $\begin{array}{l}\text { Campos } \\
\text { Cerrados }\end{array}$ & $\begin{array}{l}\text { Há um certo equilíbrio entre a vegetação } \\
\text { herbácea e a arbustiva, com composição variável } \\
\text { conforme a região, porem em geral de qualidade } \\
\text { inferior. }\end{array}$ \\
\hline Cerrados & $\begin{array}{l}\text { Encontra-se um estágio mais avançado da } \\
\text { transição entre campos e florestas, de modo que } \\
\text { predomina a vegetação arbustiva e arbórea, com } \\
\text { baixa proporção de leguminosas. Durante a seca, } \\
\text { os cerrados oferecem alimentação aproveitável, } \\
\text { porem com plantas tóxicas nocivas aos animais } \\
\text { não habituados. }\end{array}$ \\
\hline
\end{tabular}

\section{Quadro 4: Pastagens Naturais}

Fonte: Jardim (1973, p. 171)

Também existe a pastagem artificial que é aquela formada por pastos cultivados. Em geral, exige preparo do solo, por meio de destocamento, as rações, adubações, gradagem, e plantação ou semeadura. Para Marion (2010, p.50) as principais forrageiras utilizadas nos pastos são: gramíneas: capimcolonião, capim-gordura, capim-jaraguá, capim-pangola, outros capins e cereais; leguminosas: alfafa, soja, perene, siratro, carrapicho, beiço-de-boi, etc.; cactáceas: palma, mandacaru, xiquexique; outras: como a mandioca, batata-doce etc. (como alimentação suplementar).

Porém para Jardim (1973, p. 171), "as pastagens também podem ser naturalizadas, onde resultam da disseminação de forrageiras pelo próprio gado, principalmente por meio das fezes distribuídas por toda a área ocupada pelos animais". 
ZILIOTTO, M.R. et al. Estudo de caso sobre a bovinocultura de corte: uma análise baseada em custos. PUBVET, Londrina, V. 6, N. 2, Ed. 189, Art. 1270, 2012.

O produtor bovino, ao optar pela engorda com base nas pastagens, terá a obrigação de um entendimento e compreensão sistêmica de conservação e manejo do pasto, para resultados eficientes e competitivos. Pois, apesar deste sistema de produção ter um custo mais considerável, o mesmo requer cuidados especiais, onde um planejamento adequado terá um proveito máximo dos recursos naturais, minimizando os custos e tendo como produto final um animal de melhor qualidade.

O Quadro 5 demonstra que a pastagem nativa apesar de diminuir, ainda ocupa um lugar de destaque no contexto da pecuária brasileira. Pode-se afirmar que a cultivação de pastagens é improvável em algumas regiões, devido as características de seus ecossistemas.

\begin{tabular}{|l|r|r|r|r|r|r|}
\hline \multicolumn{7}{|c|}{ Evolução das áreas de pastagens (1.000 hectares). } \\
\hline \multirow{2}{*}{ REGIÕES } & \multicolumn{2}{|c|}{1970} & \multicolumn{2}{c|}{1985} & \multicolumn{2}{|c|}{1995} \\
\cline { 2 - 7 } & NATIVA & CULTIVADA & NATIVA & CULTIVADA & NATIVA & CULTIVADA \\
\hline Norte & 3.790 & 638 & 11.755 & 9.122 & 9.624 & 14.763 \\
\hline Nordeste & 22.124 & 5.751 & 23.283 & 11.866 & 19.977 & 12.100 \\
\hline Sudeste & 34.076 & 10.663 & 25.764 & 16.723 & 17.325 & 20.453 \\
\hline Sul & 17.976 & 3.637 & 15.291 & 6.142 & 13.680 & 7.017 \\
\hline Centro-Oeste & 46.410 & 9.073 & 28.992 & 30.252 & 17.444 & 45.320 \\
\hline Brasil & 124.376 & 29.762 & 105.085 & 74.105 & 78.048 & 99.652 \\
\hline
\end{tabular}

Quadro 5: Evolução das pastagens.

Fonte: Dados IBGE, , 2005b). (Cezar et al. 2005, p. 15).

As pastagens cultivadas, com o passar dos anos alargaram-se em todas as regiões do País. Conforme Cezar et al. (2005, p. 15), "essa área passou de aproximadamente 30 milhões de hectares, em 1970, para quase 100 milhões em 1995, o que significa um incremento de $233 \%$ em 25 anos, a uma taxa anual de crescimento de $9,3 \% "$. 


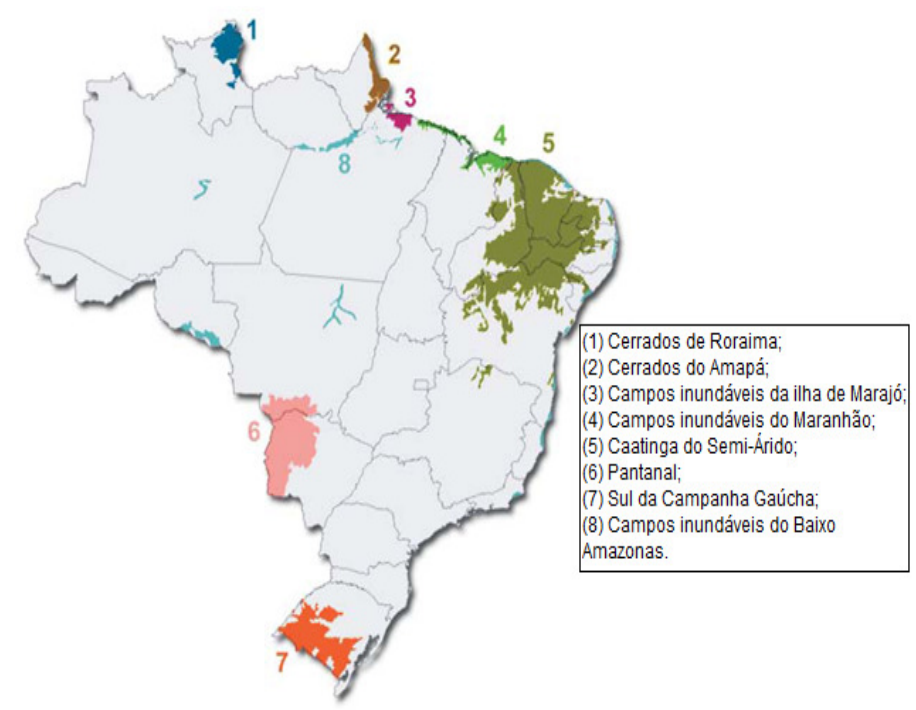

Figura 3: Regiões com predominância de pastagens nativas.

Fonte: Adaptado do IBGE (2005d). (Cezar et al. 2005, p. 26).

As pastagens podem ser nativas ou cultivadas, o Brasil é um país de grandes dimensões e com condições climáticas favoráveis para a produção de carne, pois o potencial de cultivo de pastagens é alto, o que favorece os pecuaristas, porém o uso e manejo correto das mesmas são mais do que suficiente para aumentar drasticamente a produtividade.

\subsection{Confinamento}

O confinamento é uma forma de engorda de gado de corte, além de ter muitos benefícios como, criar os bovinos em pequenos espaços, o ganho de peso é mais considerável e em um tempo mais curto.

No confinamento, o animal fica restrito a uma área pequena, portanto, é alterada a sua condição habitual de alimentação. O animal confinando recebe alimentação balanceada, contendo todos os nutrientes para atender suas necessidades de energia, com o objetivo de atingir um determinado ganho de peso diário. Com o confinamento visa-se fazer com que o animal alcance peso mais rápido, uma vez que o ganho diário deve ser maior, devido ao fato de que a perda de energia é mínima, e tendo em vista a pequena área de que dispõe para movimentação. 
ZILIOTTO, M.R. et al. Estudo de caso sobre a bovinocultura de corte: uma análise baseada em custos. PUBVET, Londrina, V. 6, N. 2, Ed. 189, Art. 1270, 2012.

O uso de confinamento, isto é utilização de sistemas intensivos para a produção de bovinos de corte, como relatado por Cezar (2005, p. 28), segundo estimativas do Instituto FNP (ANUALPEC, 2005) em 2004, foram abatidos 2,4 milhões cabeças de bovinos terminados em regime de confinamento, representando cerca de $5,17 \%$ do total de animais abatidos no País.

Através dos dados do Quadro 6 observa-se que 75\% desses animais se encontravam em Estados das regiões Centro-Oeste (MS, MT e GO) e Sudeste (SP e MG), e que os $15 \%$ restantes para completar $90 \%$ do total estavam localizados nos Estados das regiões Nordeste (BA), Sul (RS, PR e SC), Norte (TO) e Sudeste (RJ e ES). Verifica-se na Figura 17 que a proporção do abate de animais confinados, em relação ao total de animais abatidos, já é significativa em alguns Estados, considerando que na década passada era pouco expressiva, com exceção de São Paulo. (CEZAR et al. 2005, p. 29).

\begin{tabular}{|l|r|r|r|}
\hline \multirow{2}{*}{ Estados } & Abate Total & \multicolumn{2}{c|}{ Abate de animais } \\
\cline { 3 - 4 } (cabeças) & Cabeças & \% abate total \\
\hline São Paulo & $5,354,056$ & 617,000 & 11.52 \\
\hline Goiás & $4,804,016$ & 383,000 & 7.97 \\
\hline Mato Grosso do Sul & $6,381,738$ & 346,000 & 5.42 \\
\hline Mato Grosso & $4,117,092$ & 302,000 & 7.34 \\
\hline Minas Gerais & $5,391,838$ & 170,000 & 3.15 \\
\hline Bahia & $2,696,507$ & 117,000 & 4.34 \\
\hline Paraná & $3,205,459$ & 93,000 & 2.9 \\
\hline Rio Grande do Sul & $3,908,644$ & 89,000 & 2.28 \\
\hline Tocantis & $1,283,981$ & 72,000 & 5.61 \\
\hline Santa Catarina & 953,250 & 38,000 & 3.99 \\
\hline Rio de Janeiro & 615,765 & 17,000 & 2.76 \\
\hline Espírito Santo & 448,411 & 14,000 & 3.12 \\
\hline Outros Estados & $7,817,046$ & 169,000 & 2.16 \\
\hline Total & $46,977,803$ & $2,427,000$ & 5.17 \\
\hline
\end{tabular}

Quadro 6: Abate de animais terminados em confinamento em 2004.

Fonte: Adaptado do Instituto FNP (Anualpec, 2005), (Cezar ET AL. 2005, p. 29). 
A Figura 4 demonstra a engorda intensiva de bovinos no Brasil do ano de 2002 a 2010, em 2007 e 2008, apresenta uma grande expansão, sendo que em 2009 decresceu, devido a crise mundial, em 2010 a criação de gado bovino em base de confinamento voltou aos patamares de 2005.

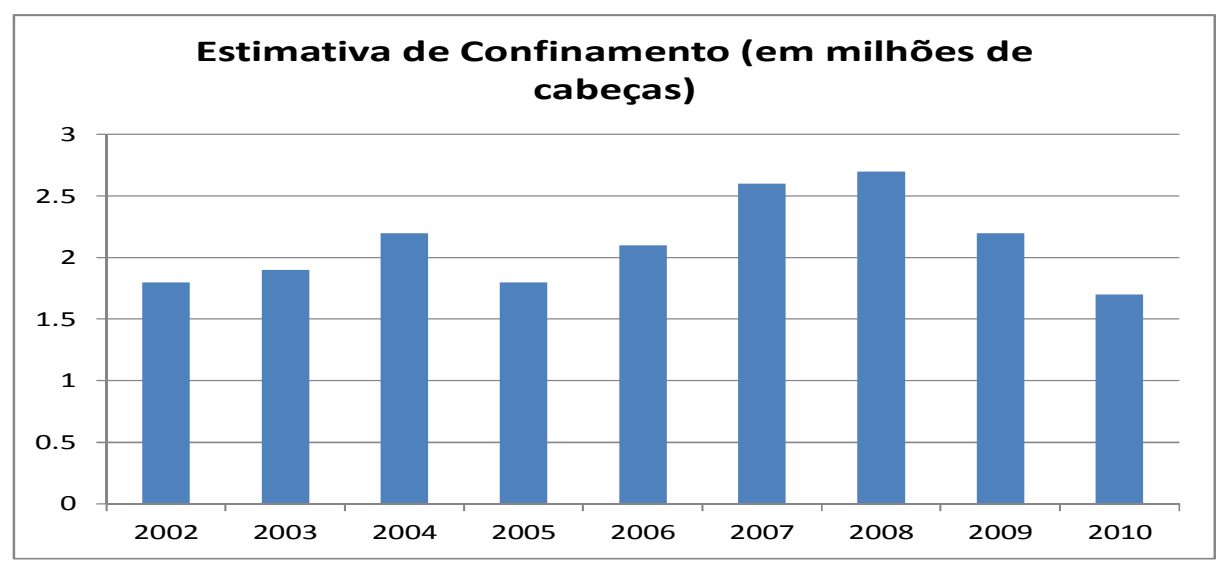

Figura 4: Efetivo de animais engordados em confinamento.

Fonte: Scot Consultoria; Anuário 2011 DBO.

As causas da retração da atividade foram os prejuízos causados em 2009, muitos confinadores ficaram desanimados, pela escassez de boi magro e pela alta nos preços dos grãos que subiam pelo menos $20 \%$. A indefinição no preço da arroba, entre janeiro e junho de 2010, justamente quando os confinadores tomam as suas decisões, a arroba do boi gordo oscilou entre $R \$$ 82,00 e $R \$ 85,00$ reais, enquanto a de boi magro apresentava alta expressiva, tendo sido ofertada a $\mathrm{R} \$ 100,00$ e $\mathrm{R} \$ 110,00$ reais, isso completou o quadro pouco favorável. (Anuário DBO, 2011, p. 20).

O desempenho da atividade em 2011 está cercado de incertezas, pois conforme Franco (2011, p. 21), a principal matéria-prima, o boi magro, continua cara, os ingredientes das rações também subiram muito, ou seja, o custo de produção aumentou bastante. Porém, há bons indícios de que o preço do boi gordo se mantenha firme, e isso é muito favorável, mas se as cotações dos animais de reposição não recuarem, as margens de lucro da atividade estarão comprometidas. (Anuário DBO, 2011, p. 21). 
ZILIOTTO, M.R. et al. Estudo de caso sobre a bovinocultura de corte: uma análise baseada em custos. PUBVET, Londrina, V. 6, N. 2, Ed. 189, Art. 1270, 2012.

No Brasil, o sistema extensivo é o que predomina, os criadores utilizam o máximo de recursos naturais para a alimentação do gado, porém a utilização do sistema intensivo, confinamento, pode ser importante para os mesmos, pois necessitam de ajustes necessários para garantir os objetivos previamente determinados.

\section{Metodologia}

O presente artigo utilizou como método de pesquisa o estudo de caso (Yin, 1994), onde buscou-se mostrar a realidade apresentada de um produtor rural da cidade de Vacaria (Nordeste do Rio Grande do Sul). Devido à escolha do estudo de caso, foi necessária a análise mais profunda de informações que foram obtidas in loco. Quanto à classificação da pesquisa, a mesma mostrouse de caráter descritiva (Vergara, 2005), pois a pesquisa buscou retratar a realidade dos fatos sem o intuito de alterá-los, também pode ser classificada de bibliográfica (pesquisa realizada em livros, manuais acadêmicos, sites etc.) e documental (devido aos dados e informações obtidos na empresa). O estudo teve como variáveis e indicadores o custo de produção do gado de pastagem e de confinamento.

\section{ESTUDO DE CASO}

Os dados analisados para a realização deste artigo são provenientes de um produtor rural da cidade de Vacaria (Nordeste do Rio Grande do Sul). O pecuarista é voltado apenas para a fase de engorda animal, isto é, a fase de terminação. Consome bois de sobre ano, com carcaça já estruturada para a fase de engorda, porém a aquisição destes animais é antecedente a esta fase, para assim poder preparar o gado. Desta forma, o pecuarista consegue planejar sua produção, para ser destinada ao confinamento ou para as pastagens cultivadas de inverno.

Neste estudo, no final de janeiro de 2011, o gado foi adquirido para posterior destinação à fase de engorda. Visto que, na região de Vacaria no mês de janeiro as lavouras de soja e milho estão no auge de sua produção, e a 
ZILIOTTO, M.R. et al. Estudo de caso sobre a bovinocultura de corte: uma análise baseada em custos. PUBVET, Londrina, V. 6, N. 2, Ed. 189, Art. 1270, 2012.

oferta de gado gordo para o abate é escassa devido a falta de vastos pastos para a engorda do boi. O rebanho fica em campos nativos para manter o peso e preencher o tempo de carência da vacinação, até ser destinado ao confinamento ou no pasto cultivado para a sua engorda.

O sistema de produção de bovinos de corte, que se destina a criação de gado para o abate deste estudo, fica em uma propriedade arrendada situada no interior do município de Vacaria distante $12 \mathrm{~km}$ da cidade. Estão os rebanhos de pasto e confinamento, porém separados por cultura.

O espaço destinado para a engorda no sistema intensivo, possui 4 hectares, e o pasto alugado para a fase de terminação dos bovinos destinados a esta cultura, possui 60 hectares.

No Quadro 7 demonstra-se o DRE do gado de pastagem desde 31 de janeiro de 2011 até 02 de agosto de 2011, os meses necessários e previstos para o rebanho de 100 cabeças, atingir o desenvolvimento necessário para venda e posterior abate. 
ZILIOTTO, M.R. et al. Estudo de caso sobre a bovinocultura de corte: uma análise baseada em custos. PUBVET, Londrina, V. 6, N. 2, Ed. 189, Art. 1270, 2012.

\begin{tabular}{|c|c|c|}
\hline \multicolumn{3}{|c|}{$\begin{array}{l}\text { DEMONSTRATIVO DO RESULTADO DO EXERCÍCIO (DRE) } \\
\text { DE } 31 \text { DE JANEIRO À } 02 \text { DE AGOSTO DE } 2011\end{array}$} \\
\hline RECEITA OPERACIONAL BRUTA & $\mathbf{R} \$$ & $164.500,00$ \\
\hline Vendas de Gado Bovino & $\mathrm{R} \$$ & $164.500,00$ \\
\hline DEDUÇÕES DE RECEITAS OPERACIONAIS BRUTAS & $\mathbf{R} \$$ & $3.783,50$ \\
\hline Funrural $(2,3 \%)$ & $\mathrm{R} \$$ & $3.783,50$ \\
\hline RECEITA OPERACIONAL LÍQUIDA & $\mathbf{R} \$$ & $160.716,50$ \\
\hline CUSTOS DAS VENDAS & $\mathbf{R} \$$ & $136.559,38$ \\
\hline Custo de Gado Bovino & $\boldsymbol{R} \boldsymbol{\$}$ & $108.500,00$ \\
\hline Custo de Aluguel de Pasto & $\boldsymbol{R} \boldsymbol{\$}$ & $17.500,00$ \\
\hline Arrendamento & $\boldsymbol{R S}$ & $4.452,00$ \\
\hline Custo de Produção & $\boldsymbol{R} \boldsymbol{\$}$ & $6.107,38$ \\
\hline Insumos & $\mathbf{R} \$$ & $1.559,00$ \\
\hline Vacinas & $\mathrm{R} \$$ & $1.429,00$ \\
\hline Brinco de Identificação & $\mathrm{R} \$$ & 130,00 \\
\hline Mão- de-Obra Direta & $\mathbf{R} \$$ & $2.965,00$ \\
\hline Mão-de-Obra & $\mathrm{R} \$$ & $2.000,00$ \\
\hline Mão-de-Obra fase Preparação & $\mathrm{R} \$$ & 840,00 \\
\hline Médico Veterinário & $\mathrm{R} \$$ & 125,00 \\
\hline Fretes & $\mathbf{R} \mathbf{\$}$ & $1.232,00$ \\
\hline Combustíveis & $\mathbf{R} \$$ & 351,38 \\
\hline Fase Preparação & $\mathrm{R} \$$ & 287,58 \\
\hline Fase Engorda & $\mathrm{R} \$$ & 63,80 \\
\hline RESULTADO OPERACIONAL BRUTO & $\mathbf{R} \mathbf{\$}$ & $24.157,12$ \\
\hline
\end{tabular}

Quadro 7: Demonstrativo do Resultado de Exercício.

Destaca-se que através do Demonstrativo de Resultado do Exercício o produtor rural obteve um resultado operacional de $\mathrm{R} \$ 24.157,12$, visto que em média lucra-se $\mathrm{R} \$ 4.026,18$ por mês em cada lote de 100 cabeças vendidas, sendo que neste valor estão incluídos todos os custos atribuídos para estes animais.

É importante enfatizar, que o valor da venda apurado para este estudo, é de uma previsão de preço de mercado, estima-se em $\mathrm{R} \$ 3,50 / \mathrm{Kg}$, conforme Cotações do Mercado Futuro, desta forma compreende-se que a carne produzida pelo pecuarista, independendo o método de produção utilizado, terá um preço de venda semelhante para ambos os sistemas, então se entende que - levantamento e análise dos custos é de extrema importância perante a situação de mercado, para assim não apresentar riscos para o negócio. 
ZILIOTTO, M.R. et al. Estudo de caso sobre a bovinocultura de corte: uma análise baseada em custos. PUBVET, Londrina, V. 6, N. 2, Ed. 189, Art. 1270, 2012.

\subsection{Custo de produção do gado de corte de confinamento}

No Quadro 8 demonstra-se o DRE do gado de confinamento observandose o período necessário para que o rebanho possa atingir o peso adequado para sua venda e posterior abate, bem como, leva-se em conta que são 100 cabeças.

\begin{tabular}{|c|c|c|}
\hline \multicolumn{3}{|c|}{$\begin{array}{l}\text { DEMONSTRATIVO DO RESULTADO DO EXERCICIO (DRE) } \\
\text { DE } 31 \text { DE JANEIRO À } 08 \text { DE JULHO } 2011\end{array}$} \\
\hline RECEITA OPERACIONAL BRUTA & $\mathbf{R} \$$ & $182.000,00$ \\
\hline Vendas de Gado Bovino & $\mathrm{R} \$$ & $182.000,00$ \\
\hline DEDUÇÕES DE RECEITAS OPERACIONAIS BRUTAS & $\mathbf{R} \mathbf{S}$ & $4.186,00$ \\
\hline Funrural $(2,3 \%)$ & $\mathrm{R} \$$ & $4.186,00$ \\
\hline RECEITA OPERACIONAL LÍQUIDA & $\mathbf{R} \$$ & $177.814,00$ \\
\hline CUSTOS DAS VENDAS & $\mathbf{R} \$$ & $171.059,78$ \\
\hline Custo de Gado Bovino & $\boldsymbol{R} \boldsymbol{\$}$ & $124.000,00$ \\
\hline Arrendamento - Fase Preparação & $\boldsymbol{R} \boldsymbol{\$}$ & $4.452,00$ \\
\hline Arrendamento & $\boldsymbol{R} \boldsymbol{\$}$ & $2.500,00$ \\
\hline Custo de Produção & $\boldsymbol{R} \boldsymbol{\$}$ & $40.107,78$ \\
\hline Insumos & $\mathbf{R} \$$ & $34.673,00$ \\
\hline Rações & $\mathrm{R} \$$ & $32.700,00$ \\
\hline Vacinas & $\mathrm{R} \$$ & $1.843,00$ \\
\hline Brinco de Identificação & $\mathrm{R} \$$ & 130,00 \\
\hline Mão- de-Obra Direta & $\mathbf{R} \$$ & $3.215,00$ \\
\hline Mão-de-Obra & $\mathrm{R} \$$ & $2.025,00$ \\
\hline Mão-de-Obra Diversa & $\mathrm{R} \$$ & 225,00 \\
\hline Mão-de-Obra fase Preparação & $\mathrm{R} \$$ & 840,00 \\
\hline Médico Veterinário & $\mathrm{R} \$$ & 125,00 \\
\hline Fretes & $\mathbf{R} \mathbf{P}$ & $1.232,00$ \\
\hline Combustíveis & $\mathbf{R} \mathbf{S}$ & 687,78 \\
\hline Fase Preparação & $\mathrm{R} \$$ & 287,58 \\
\hline Fase Engorda & $\mathrm{R} \$$ & 400,20 \\
\hline Energia & $\mathbf{R} \$$ & 300,00 \\
\hline RESULTADO OPERACIONAL BRUTO & $\mathbf{R} \$$ & $6.754,22$ \\
\hline
\end{tabular}

\section{Quadro 8: Demonstrativo do Resultado de Exercício.}

Após a verificação de todos os custos gerados para a engorda de bovinos com base no sistema intensivo, nota-se que os gastos são expressivos, devido à necessidade de ração para a alimentação. O milho nesta mesma época do 
ZILIOTTO, M.R. et al. Estudo de caso sobre a bovinocultura de corte: uma análise baseada em custos. PUBVET, Londrina, V. 6, N. 2, Ed. 189, Art. 1270, 2012.

ano passado custava em média $\mathrm{R} \$ 15,50$ por cada saca de $60 \mathrm{~kg}$ no Rio Grande do Sul, já este ano custa R\$29,00/60 kg.

\subsection{Comparação dos manejos}

Após o estudo e análise do manejo de gado de corte terminado em pastagem e em confinamento, chega-se a seguinte definição dos custos demonstrado Quadro 9.

\begin{tabular}{|l|rr|rr|}
\hline \multicolumn{4}{|c|}{ COMPARATIVO DA LUCRATIVIDADE } \\
\hline & \multicolumn{2}{|c|}{ Pastagem } & \multicolumn{2}{c|}{ Confinamento } \\
\hline Receita Bruta & $\mathrm{R} \$$ & $\mathbf{1 6 4 . 5 0 0 , 0 0}$ & $\mathrm{R} \$$ & $182.000,00$ \\
\hline Deduções & $\mathrm{R} \$$ & $3.783,50$ & $\mathrm{R} \$$ & $4.186,00$ \\
\hline Custos & $\mathrm{R} \$$ & $\mathbf{1 3 6 . 5 5 9 , 3 8}$ & $\mathrm{R} \$$ & $171.059,78$ \\
\hline Receita Líquida & $\mathrm{R} \$$ & $24.157,12$ & $\mathrm{R} \$$ & $6.754,22$ \\
\hline
\end{tabular}

Quadro 9: Comparativo da lucratividade entre os manejos.

A diferença entre os dois sistemas é de $R \$ 17.402,90$, com vantagem para o gado engordado na pastagem, um valor consideravelmente alto mesmo levando em conta o menor tempo para a engorda no confinamento.

\section{CONSIDERAÇÕES FINAIS}

Considerando a situação atual de mercado para os produtores de carne, os custos de insumos para os que utilizam o confinamento, estão relativamente altos, como é o caso do milho, que em 2010 na mesma época o preço era $R \$ 15,50$ a saca de $60 \mathrm{~kg}$, atualmente o preço é de $\mathrm{R} \$ 29,00$. Esta alta levou a que muitos pecuaristas não confinassem este ano, visto que os indicadores já alertavam estes riscos de produção.

Mesmo o confinamento tendo uma receita maior, esta não foi suficiente para gerar uma lucratividade mais significante quanto ao gado de pastagem, isso se deve aos os custos do confinamento que estão relativamente altos para o primeiro semestre de 2011. 
ZILIOTTO, M.R. et al. Estudo de caso sobre a bovinocultura de corte: uma análise baseada em custos. PUBVET, Londrina, V. 6, N. 2, Ed. 189, Art. 1270, 2012.

O sistema de confinamento deve ser gerenciado, com cuidado, para não correr riscos com prejuízos, o produtor deve estar atendo aos preços dos insumos para a produção, ou o conhecimento de componentes mais baratos para minimizar os custos.

Desta forma conclui-se que o produtor rural que possui pastagem para a terminação de todo o rebanho, consequentemente terá um manejo mais lucrativo.

Finalizando, o sistema de confinamento é um manejo inviável considerando os custos, mas em relação aos seus benefícios se torna o sistema mais vantajoso. Contudo na realidade do Brasil, esta modalidade de confinamento ainda é de baixa escala, devido a dominação de recursos naturais, portanto, para os produtores que dispuserem de pastagem para todo o manejo e em boa parte do ano, terá uma produção mais econômica.

\section{REFERENCIAS BIBLIOGRAFICAS}

CEZAR, Ivo Martins; QUEIROZ, Haroldo Pires; S.THIAGO, Luiz Roberto Lopes de; CASSALES, Fernando Luis Garagorry; COSTA, Fernando Paim. Sistemas de produção de gado de corte no Brasil: uma descrição com ênfase no regime alimentar e no abate / Ivo Martins Cezar... [et al.].. Campo Grande, MS : Embrapa Gado de Corte, 2005.

CHIELLE, Daniel Padoin, BARBOZA, Fabrício da Silva, VIVAN, Gisele Aparecida, LUDWIG, Rafael, ZANELLA, Pedro Augusto, QUADRO, Maurizio Silveira, PEREIRA-RAMIREZ, Orlando. Metodologia de Balanceamento de Dietas para Bovinos do Tipo Gado de Corte. Disponível em http://www.ufpel.edu.br/cic/2008/cd/pages/pdf/EN/EN_01204.pdf (Acessado em 05.05.2011).

CORRÊA, Cynthia Cândida; VELOSO, Aline Freitas; LIMA, Beltran Martins; COTA, Ronailson Garcia; FIGUEIREDO NETO, Leonardo Francisco. Gerenciamento da Pecuária de Corte no Brasil: Cria, Recria e Engorda de Bovinos a Pasto. Disponível em www.sober.org.br/palestra/13/762.pdf.

DALPIAS, Luís Cezar. População bovina. Inspetoria Veterinária de Vacaria, dados obtidos no dia 26 de abril de 2011, pessoalmente.

DUTRA, René Gomes. Custos: uma abordagem prática. 5. Ed. São Paulo: Atlas, 2003.

EUCLIDES FILHO, Kepler. A pecuária de corte no cerrado brasileiro. Disponível em <http://simposio.cpac.embrapa.br/simposio/projeto/palestras/capitulo_17.pdf>. Acesso em: 29.04.2011.

EUCLIDES FILHO, Kepler. A Pecuária de Corte no Brasil: Novos Horizontes, Novos Desafios. Campo Grande: Embrapa Gado de Corte, 1997.

EUCLIDES FILHO, Kepler. Melhoramento genético animal no Brasil: fundamentos, história e importância. Campo Grande: Embrapa Gado de Corte, 1999. 
EUCLIDES FILHO, Kepler. Produção de bovinos de corte e o trinômio genótipo-ambientemercado. Campo Grande: Embrapa Gado de Corte, 2000.

EUCLIDES FILHO, Kepler. Boas práticas na produção de bovinos de corte. Campo Grande: Embrapa Gado de Corte, 2002.

FERREIRA, José Antonio Stark. Contabilidade de custos. São Paulo: Pearson Prentice Hall, 2007.

GLOBO RURAL. Agropecuária, Negócios e vida no campo.

GOMES, Marcos. Gênero Clostridium ssp. Disponível em http://www6.ufrgs.br/labacvet/files/Clostridium201101 0.pdf (Acessado em 09.06.2011).

GRANDE MANUAL GLOBO. Agricultura, pecuária e receituário industrial. Volume 4. Porto Alegre: Editora Globo SA, 1978.

GRANDE MANUAL GLOBO. Agricultura, pecuária e receituário industrial. Volume 5. Porto Alegre: Editora Globo SA, 1978.

HANSEN, Don R., MOWEN, Maryanne M. Gestão de Custos / Don R. Hansen, Maryanne M. Mowen; tradução Robert Brian Taylor: revisão técnica Elias Pereira. 1 reimp. da 1 ed. São Paulo: Pioneira Thomson Learning, 2003.

JARDIM, Valter Ramos. Curso da bovinocultura. 4 ed. Campinas, Instituto Campineiro de Ensino Agrícola, 1973.

KICHEL, Armindo Neivo, KICHEL, Andrei Gervini. Requisitos Básicos para Boa Formação e Persistência de Pastagens. Disponível em http://www.cnpgc.embrapa.br/publicacoes/divulga/GCD52.html, (Acessado em 13.05.2011).

KROETZ, Cesar Eduardo S. Apostila de Contabilidade de Custos I. Disponível em http://www.netsaber.com.br/apostilas/apostilas/1029.pdf.

LAZZARINI NETO, Sylvio. Manejo de Pastagens. 2. Ed. Viçosa : Aprenda Fácil, 2000.

LOBATO, Francisco e ASSIS, Ronnie a. Clostridioses dos Animais. Disponível em http://www.ivis.org/proceedings/abmg/2005/pdf07.pdf. (Acessado em 27.05.2011).

LOPES, Marcos Aurélio; CARVALHO, Franciscal de Melo. Custo de Produção do Gado de Corte. Disponível em http://www.editora.ufla.br/site/ adm/upload/boletim/bol 47.pdf (Acessado em 19.04.2011).

MAHER, Michael. Contabilidade de custos: criando valor para a administração. Michael Maher: tradução José Evaristo dos Santos. São Paulo: Atlas, 2001.

MARCANTONIO, Getúlio. A pecuária Rio-Grandense e sua perspectiva. Porto Alegre, Sulina, 1987.

MARION, José Carlos. Contabilidade Rural. Contabilidade Agrícola, Contabilidade da Pecuária, Imposto de Renda - Pessoa Jurídica. 12. Ed. São Paulo: Atlas, 2010.

MARLEEN, Felius. 1985. A Origem das Raças Bovinas. Cattle Breeds of the World, Genus Bos, by Marleen Felius traduzido por Paulo Reis. Disponível em

http://www.transgen.com.br/artigo_visualiza.php?id_artigo=4 (Acessado em 01.05.2011).

MARTIN, Luiz Carlos Tayarol. Confinamento de bovinos de corte. São Paulo: Nobel, 1987.

MARTINS, Eliseu. Contabilidade de Custos. 9. ed. 6.reimpr. São Paulo: Atlas, 2006.

NEPOMUCENO, Fernando. Contabilidade rural e seus custos de produção. São Paulo: IOBThomson, 2004.

NEUMANN, Michel et al. A cadeia produtiva da carne bovina: análise de formação de preços da carne bovina no Rio Grande do Sul. Disponível em 
http://www.ufrgs.br/zootecnia/nespro/Anais\%20I\%20Jornada/TEXTOS\%20EM\%20PDF/A\%20c adeia\%20produtiva\%20da\%20carne\%20bovina.pdf (Acessado em 05.05.2011).

NOTICIÁRIO Tortuga, Edição 471. Ano 55. SET/OUT. 2010.

NOTICIÁRIO Tortuga, Edição 473. Ano 57. Fev/março 2011.

PERSPECTIVA da Agropecuária para 2011, e Balanço de 2010

http://www.sindicatorural.com/arquivos/conteudo/balancos-e-perspectivas-2010_vweb.pdf (Acessado em 25/04/2011).

PINTO, Antônio Luiz de Toledo; WINDT, Márcia Cristina Vaz dos Santos; CÉSPEDES, Lívia. Código Tributário Nacional e Constituição Federal. Obra coletiva de auditoria da Editora Saraiva. 14 edição. São Paulo; Saraiva, 2008. (Legislação brasileira).

PITUCO, Edviges Maristela. A importância da Febre Aftosa em Saúde Pública. Disponível em http://www.sic.org.br/PDF/Febre Aftosa.pdf. (Acessado em 21.05.2011)

PREÇO do boi Gordo no Rio Grande do Sul. Disponível em http://www.ourofino.com/saudeanimal/ruminantes/noticias/2011/04/07/preco-do-boi-gordo-no-rs.html (Acessado em 26.05.11).

PREFEITURA DE VACARIA, Rio Grande do Sul. 2011. http://www.prefeituradevacaria.com.br/vacaria/index.php (Acessado em 26.04.2011).

ROCHA JÚNIOR, Vicente Ribeiro e CAPELLI, Edilson Rezende, editores. - Viçosa, UFV; DZO; DPI, 2001. Alimentos Volumosos. Disponível em http://www.agencia.cnptia.embrapa.br/Agencia8/AG01/arvore/AG01_344_217200392415.htm I (Acessado em 20.05.2011).

RODRIGUES, Gilman Viana. A importância socioeconômica da pecuária de corte no Brasil. Disponível em

http://www.agricultura.mg.gov.br/files/apresenta2009/PECUARIA_DE_CORTE.pdf. (Acessado em 16.04.2011).

SAAD, Rafael Antonio. Agropecuária: A grande virada - três ações para revolucionar seu empreendimento: fertilização, manejo e uso de forrageiras adequadas. Porto Alegre: AGE, 2007.

SANTOS, Cleiton. Anuário Brasileiro da Pecuária 2007. Santa Cruz do Sul: Editora Gazeta Santa Cruz, 2007.

SANTOS, Luana Maria. ROCHA, Jessé Ribeiro. RODIGUES, Clayton F.M. CANESIM, Renato. PINHEIRO, Juliana da Silva. PINHEIRO JÚNIOR, Osni Álamo. Carbúnculo Hemático. Disponível em http://www.revista.inf.br/veterinaria10/revisao/edic-vi-n10-RL13.pdf (Acessado em 29.05.2011).

SOUZA, Domingos Carvalho De. A utilização da informação contábil na atividade da pecuária do estado do rio grande do norte: um enfoque nos demonstrativos gerados para a tomada de decisão. , NATAL 2004. Disponível em

http://bdtd.bczm.ufrn.br/tedesimplificado/tde_arquivos/26/TDE-2007-01-26T061357Z513/Publico/DomingosCS.pdf. (Acessado em 19.04.2011).

UFRGS. Diagnóstico de sistemas de produção de bovinocultura de corte do estado do Rio Grande do Sul: relatório. Porto Alegre: 2005. 265 p.

VANDERBECK, Edward J. Contabilidade de Custos. 11. Ed. São Paulo: Pioneira Thomson Learning, 2003.

VERGARA, Sylvia Constant. Métodos de pesquisa em administração. São Paulo: Atlas,2005. 
VICECONTI, Paulo Eduardo Vilchez. Contabilidade de custos: um enfoque direto e objetivo / Paulo Eduardo V. Viceconti, Silvério das Neves. 7 ed. ver. e ampl. São Paulo: Frase Editora, 2003.

VIDOR, Ana Carla Martins. Análise da movimentação de bovinos no Rio Grande do Sul em 2009. Disponível em

http://www.saa.rs.gov.br/uploads/1284486229Informativo_Tecnico_DPA 02 01_maio_201 0.pdf . (Acessado em 01.05.2011).

WILLIAMS, D. W. Produção de gado de corte no sul dos EUA. Rio de Janeiro: USAID/Livraria Freitas Bastos, 1967.

YIN, R. K. Estudo de caso: planejamento e métodos. Porto Alegre: Bookman, 2001. 